\title{
Risk Analysis, Pilot Motivation, and Decision-Making: Application of the PAVE Personal Minimums Checklist to Pilot Decision-Making in Three General Aviation Accidents
}

\author{
Lorelei E. Ruiz \\ Southern Illinois University Carbondale
}

\begin{abstract}
This paper addresses the relative effects of risk and pilot motivation on decisions made by three general aviation pilots. Using the PAVE (Pilot, Aircraft, environment, External pressures) personal minimums checklist, various risk elements related to the flights and information available to the pilots prior to/during flight are considered. The motivation behind each pilot's decision to go ahead with the flight in spite of adverse conditions is also discussed. Use of the checklist as an in-flight decision-making tool, as well as go/no-go decision-making are considered, and suggestions for further research are offered.
\end{abstract}

\section{INTRODUCTION}

A recent study of general aviation aircraft accidents occurring in 1996 by the National Transportation Safety Board (NTSB, 1999) indicates that $83 \%$ of all fatal general aviation accidents that year were attributable to pilot performance. A number of those accidents were due to such events as encounters with weather (13.4\%), loss of aircraft control $(31.4 \%)$, and collision with terrain (11.2\%) (NTSB, 1999). Such occurrences are often a result of poor decision-making on the part of the pilot-incommand. Many agencies and organizations within the aviation industry offer programs and literature aimed at teaching pilots to recognize their own tendencies to make poor decisions. The combined efforts of the Federal Aviation Administration (FAA) and various aviation-oriented organizations have resulted in the creation of many training aids aimed at improving pilot decision-making skills.

In 1987, the FAA published a series of manuals pertaining to aeronautical decision-making (ADM). These publications present ADM concepts (e.g., hazardous attitudes, risk elements) for training purposes, and were the results of twelve years of research, testing, and development (FAA, 1991). In the manual for student and private pilots, the FAA (1987) defines ADM as "the ability to search for and establish the relevance of all available information regarding a flying situation, to specify alternative courses of action, and to determine expected outcomes from each alternative."

The motivation is to choose and authoritatively execute a suitable course of action within the time frame permitted by the situation. The word "suitable" means an alternative consistent with societal norms, and "action" includes no action, some action, or action to seek more information. (p.4)

The manual recognizes that the ability to make good decisions is affected by stress. Both physiological and psychological stresses impair decision-making by dividing the pilot's attention between flight duties and distractions. It also identifies five categories of risk factors that pilots should consider when contemplating flight.

In 1996, Kirkbride, Jensen, Chubb, 
and Hunter published a personal minimums tool to aid a pilot in risk evaluation when making a go/no-go decision. It identifies six categories of risk factors, similar to those in the FAA's manual. Further collaboration between the FAA, The Ohio State University, and King Schools resulted in the PAVE (Pilot, Aircraft, environment, External pressures) personal minimums checklist pamphlet, available through the FAA (1996). This checklist (see Appendix) is to be tailored to a specific pilot's needs based on experience, certification, skill, and knowledge level. In many cases, only the minimum requirements for a flight operation (in terms of pilot certification, weather conditions, etc.) are stipulated in the regulations or aircraft manual. Less experienced pilots may wish to set more conservative minimums for themselves until they gain more familiarity with the flight environment. For example, while a flight may be legally conducted under visual flight rules with only one to three miles of visibility, depending on the operation (General Operating \& Flight Rules, 2001), a new pilot may not feel comfortable with a visibility of less than five miles or more. The PAVE checklist is designed to allow the pilot to devise a personal set of minimums to be referred to prior to flight. The checklist can be filled out at any time, allowing the pilot to think about each element without the pressure of an imminent flight. A 1998 study sponsored by the FAA's Office of Aviation Medicine (OAM) (Jensen, Guilkey, \& Hunter, 1998) found that, within the limitations of the study, pilots believe such training aids to be helpful in making the go/no-go decision.

The purpose of this paper is twofold. First, using the PAVE go/no-go decision-making tool to gauge the risks associated with the flights, it discusses the effects of motivation on decisions made by three general aviation pilots. Second, it suggests the effectiveness of the PAVE checklist as an in-flight as well as pre-flight decision-making tool.

\section{ACCIDENT SUMMARIES}

The three accidents chosen for this study occurred in 1996. Summaries of the three accidents are available on the NTSB's website, www.ntsb.gov. In each of the three accidents, the pilot-in-command (PIC) made a decision to either initiate or continue flight in spite of evidence that such a decision was not wise.

\section{Accident 1}

According to the final report adopted by the NTSB (1997), the aircraft departed Half Moon Bay, CA, on the morning of April 10, 1996, on the first leg of what was to be an attempt to set a world record for the youngest pilot to fly across the United States. Aboard the aircraft were an instructor pilot acting as PIC, the seven-year-old pilottrainee, and one passenger, the father of the pilot-trainee. The trip was to last seven days, with stops planned around visits to relatives and several public events. On the evening of April 10th, the aircraft landed at Cheyenne, WY, its final destination for the day. Takeoff the next morning was initially planned for 0615 local time in order to depart the area before an advancing storm front arrived (NTSB, 1997).

On the morning of April 11th, media reporters interviewed both the PIC and pilot trainee prior to the flight. At 0813 local time, the PIC called for taxi instructions. At 0820, he was cleared for takeoff on a special visual flight rules (VFR) clearance as rain associated with the approaching storms had reduced tower visibility to $23 / 4$ miles. After takeoff, the aircraft turned right toward an easterly heading. As the aircraft rolled out of the turn, witnesses said it suddenly descended into the ground in an almost vertical attitude (NTSB, 1997). 
The final accident report was adopted by the NTSB almost one year after the accident. Upon conclusion of the investigation, the NTSB (1997) determined that:

1. The probable cause of this accident was the pilot in command's improper decision to take off into deteriorating weather conditions (including turbulence, gusty winds, and an advancing thunderstorm and associated precipitation) when the airplane was overweight and when the density altitude was higher that he was accustomed to, resulting in a stall caused by failure to maintain airspeed. (p. 53)

2. A tightly scheduled flight itinerary and the pressures of media commitments were listed as contributing factors.

\section{$\underline{\text { Accident } 2}$}

On June 12, 1996, the pilot and her husband flew from Augusta, $\mathrm{ME}$, to Bowling Green, $\mathrm{OH}$, with an en route fuel stop at Cortland, NY (NTSB, 1996a). The pilot was in the process of moving from Augusta to Bar Harbor, ME, and the purpose of the flight was to pick up a family member who would help with the move. On June 13, 1996, the pilot and her two passengers departed Bowling Green, $\mathrm{OH}$, and arrived again at Cortland, NY, for fuel that afternoon. The accident flight was to be the final leg of the return to Augusta, ME.

The pilot initially contacted the Buffalo Flight Service Station (FSS) at 1910 local time for a weather briefing and learned of a line of thunderstorms between Cortland, NY, and her destination, Augusta, ME. Subsequent calls placed by the pilot to the FSS at 2216 and 0035 local time indicated that the storms were still present. At 0134, the pilot filed an IFR flight plan with the
FSS and, at 0223, requested her IFR clearance. She was given a clearance with a 0245 void time. The flight departed the Cortland County Airport at about 0240 and flew into rising terrain north of the departure end of Runway 6 (NTSB, 1996a).

The NTSB determined that the cause of the accident was "the pilot [sic] failure to maintain directional control of the airplane which resulted in the airplane striking trees. Contributing factors were the pilot's spatial disorientation, dark night conditions, fog, and the pilot's self-induced pressure to reach the destination" (1996b).

\section{$\underline{\text { Accident } 3}$}

On August 2, 1996, the pilot and a passenger departed Friday Harbor, WA, for Medford, OR, so the pilot could manage a bowling tournament scheduled to occur at his place of business (NTSB, 1996c). Several phone calls placed to the Seattle FSS indicated that VFR conditions would not remain through the next morning, so the pilot faced the decision of flying home that night before the weather moved in or waiting two days. The pilot opted to fly home that night, but upon contacting Seattle FSS at 0041 local time in flight to open his flight plan, he learned that conditions along his route of flight had deteriorated much more quickly than had been anticipated. He opted to continue to see what the weather really looked like. Approximately 40 minutes later, radar indicated that the aircraft entered a descending left turn at a high groundspeed and descent rate. Seattle Approach Control received a broken radio call from the pilot requesting help. The aircraft disappeared from radar, and was found in a residential area in the Purdy, WA area, six miles from the filed flight path (NTSB, 1996c).

The NTSB determined that the cause of the accident was "[ $\mathrm{t}]$ he noninstrumentrated pilot's continuation of VFR flight into 
instrument meteorological conditions which led to pilot spatial disorientation and loss of control of the aircraft. Factors were: pilot self-induced pressure, night conditions, low ceilings, and the pilot's lack of total instrument time" (NTSB, 1996d).

\section{METHODOLOGY}

The three NTSB aircraft accident reports considered here were selected for analysis based on the existence of a variety of external pressures. First, the PAVE checklist was applied to information available to the pilots to determine specific risk factors associated with each flight. Then, the particular motivating force behind each pilot's decision to proceed with flight was contrasted against those risk factors. Finally, those three cases were compared to a fourth flight in which a decision to discontinue flight was made.

\section{ANALYSIS}

Analysis shows that various risk factors existed that should have led the pilots to consider the wisdom of the decisions made. Tables 1 through 4 illustrate the known risk factors as compared to the PAVE checklist; Table 1 compares known pilot information, Table 2, known aircraft information, Table 3, known environment information, and Table 4, known external pressures. In spite of these risks, the motivation to complete flight was strong enough to override any consideration of risk.

\section{Accident 1}

\section{PAVE Checklist}

$\underline{\text { Pilot }}$

According to the NTSB (1997), while the PIC was properly certified for the flight, his lack of sleep during the three days prior to the trip led to fatigue. He also had limited experience operating out of high density altitude airports such as Cheyenne ( NTSB, 1997). As indicated previously, the PIC may have encountered both physiological and psychological stresses. The April 10 departure from Half Moon Bay Airport occurred at 0700 local time. Neither the PIC nor the pilot trainee had received much sleep the night prior to the flight. Such fatigue, while not identified as a contributing factor in the accident, is recognized as having an adverse effect on decision-making (NTSB, 1997). The very nature of the trip, with the tight schedule and all of the media attention, would have placed psychological stress on the PIC. The NTSB (1997) did recognize this as being a factor in the accident. Evidence of the effects of this stress on the PIC's abilities comes from videotapes of the aircraft prior to takeoff and from testimony from the air traffic controller on duty. According to the report, the PIC:

. . . started the airplane engine while the nosewheel was still chocked; requested a taxi clearance without having obtained the ATIS [automatic terminal information service]; read back a radio frequency incorrectly; accepted a radio frequency that he could not dial on his radio; failed to acknowledge, as requested, the weather information provided by the controller; asked "are we going the right way"; failed to stop at the end of the runway; and used incorrect phraseology when he requested a "special IFR [instrument flight rules]" clearance. (NTSB, 1997, p. 41)

At the time of the accident, ADM was not a required aeronautical knowledge area for certification. However, it should be noted that the PIC of the accident flight had completed an FAA approved flight 
instructor refresher course, including a onehour section on weather and a one-hour section on human factors in aeronautical decision-making, in the month prior to the accident (NTSB, 1997).

\section{Aircraft}

The accident aircraft was a 1975 Cessna 177B. While the aircraft carried adequate fuel and the pilot was familiar with the aircraft, the aircraft performance data appear to have been ignored to an extent (see Table 2). Given the nature and length of the trip, extra equipment was loaded on the plane, including suitcases of clothing, a video camera and film, and food and beverages (NTSB, 1997). The aircraft was found to be overweight by 96 pounds at takeoff, and estimated to be 84 pounds overweight at the time of impact (NTSB, 1997). An increase in aircraft weight will increase stall speed, decrease climb performance, and increase takeoff distances (Hurt, 1965). Consideration of these facts, along with the environmental conditions existing at the time, should have also led the PIC to consider delaying takeoff.

\section{Environment}

The environment that existed at the time of the accident, with approaching thunderstorms, was not conducive to visual flight in a light aircraft. The April 11th flight from Cheyenne was originally to have departed at 0615 local time to avoid the approaching weather system. However, the PIC did not leave the hotel until 0622 and the pilot trainee and her father did not leave until 0714. At 0801, the PIC placed a call to the Casper, WY, Automated Flight Service Station (AFSS). The AFSS briefer indicated deteriorating weather conditions due to thunderstorms just west of the airport with no significant improvement for a while. When the aircraft began its takeoff roll at 0820, the storm system was closing in, with two lightning strikes recorded at the time of takeoff, .5 and 1.2 miles west of the airport (NTSB, 1997).

\section{External pressures}

The external pressures associated with this flight included a record setting attempt with a full itinerary and scheduled media obligations. The trip was to begin on April 10, 1996, at Half Moon Bay and return to Half Moon Bay on April 17 with overnight stays in Cheyenne, WY, Ft. Wayne, IN, Falmouth, MA, Clinton, MD, Lakeland, FL, Houston, TX, and Sedona, AZ. The Massachusetts and Texas stopovers coincided with visits to relatives, and the Florida stopover coincided with the annual Sun ' $n$ Fun fly-in. There were also 15 planned intermediate fuel stops. In an interview with NTSB investigators, the father of a boy who had previously set a 'youngest pilot record' stated that during their record trip "there were media people waiting at nearly every stop. . they were distracting, irritating, asked the same questions all the time, and became a major distraction from flying duties" (NTSB, 1997, p.32). There is evidence that such media distractions affected both the accident flight and another flight previous to the record attempt. There were interviews with media the evening before and the morning of the accident flight, and papers found in the shirt pocket of the pilot trainee's father indicated several subsequent scheduled media interviews, "including one scheduled for the evening of the accident in Ft. Wayne, Indiana, and another for the next evening in Massachusetts" (NTSB, 1997, p. 25). In a previous orientation flight with media representatives, it was reported that the preflight engine runup was neglected and that a door on the aircraft was discovered to be open in flight (NTSB, 1997).

Beginning with the planning stage of the flight, it is obvious that the plan for 
the trip was too tight to take into consideration any unforeseen events (weather, illness, mechanical problems) that might cause a delay. Given the goal of completing the flights before the pilot trainee's eighth birthday on May 5th, it would appear that sufficient time existed for the trip to be completed safely. A conscious decision during the planning phase to sacrifice the intended schedule in response to adverse conditions could have prevented the accident. While there is evidence that the PIC discussed the possibility of flight delays with another pilot, his wife, and a friend, there is no confirmation that these possibilities were seriously discussed with others, including the pilot trainee or her family (NTSB, 1997).

\section{Accident 2}

Pilot

According to the NTSB (1996a), the pilot of the accident aircraft held a commercial pilot certificate with airplane single- and multi-engine land and instrument ratings and a flight instructor certificate with airplane single-engine land and instrument airplane ratings. The addition of the multi-engine rating to her commercial certificate is the last known flight review and instrument proficiency check she received. Her recent instrument flight experience was unknown, so while she was properly certified for the flight, her currency was undetermined.

Inspection of the previous day's activities indicate that this pilot also was probably in a fatigued state when the takeoff was attempted. The June 13 flight departed Bowling Green, $\mathrm{OH}$, in the afternoon and arrived at Cortland, NY, where a fuel purchase was made at 1609 local time. The first call to Buffalo FSS for a weather briefing took place at 1910. At 2001, the pilot and her passengers checked into a local motel and got a 0030 wake-up call on June
14. At 0130, a cab was dispatched to take the pilot and passengers from the motel to the airport. At 0223, the pilot received an IFR clearance from the Buffalo FSS along with a 0245 void time. The aircraft departed the Cortland airport at about 0240 local time (NTSB, 1996a).

\section{$\underline{\text { Aircraft }}$}

The accident aircraft was a 1956 Piper PA-23-150 (NTSB, 1996a). According to witnesses, the pilot experienced difficulty starting the left engine at the Cortland airport on June 12 and difficulty starting both engines at the Bowling Green airport on the afternoon of June 13. Once started, however, the engines appeared to run smoothly. The aircraft had been fueled for the flight, and the NTSB narrative makes no mention of improper weight and balance (1996a). Another pilot reported that on previous occasions, the aircraft had experienced electrical problems, including loss of interior lighting. Also, the instrument panel was not laid out in a "T" arrangement, but all instruments were in the locations they were in when the aircraft was built.

\section{Environment}

In each of three phone calls placed to the Buffalo FSS, the pilot was advised of a line of thunderstorms between Cortland, NY, and her destination, Augusta, ME. Automated weather observing system (AWOS) observations prior to and at the time of the flight reported lowering ceilings and visibilities. Between 0001 and 0141 local time, cloud cover dropped from a 300 foot scattered layer to a 100 foot overcast ceiling, and visibility dropped from $1 \frac{1}{4}$ miles to less than $1 / 4$ mile. The 100 foot ceiling and $1 / 4$ mile visibility remained until 0521 local time, almost three hours after the accident (NTSB, 1996a).

Of interest is the existence of an IFR departure procedure and published non- 
standard takeoff minima of a 400-foot ceiling and 2 mile visibility (NTSB, 1996a). Nonstandard takeoff minima and departure procedures are published when obstacles exist in the vicinity of the airport. While the Part 91 flight was not required to follow these minima, their existence indicates a need for extra caution during the takeoff phase of flight.

\section{External pressures}

The pilot was scheduled by her employer to be on duty at 0900 on June 14 for scenic flights. There were no such flights actually scheduled for that time, and the pilot knew another pilot was available to cover the flight schedule. Also, according to a family member, "the pilot and her husband were under pressure from their current landlord to evacuate their present housing by the end of the day on June 14, 1996" (NTSB, 1996a). Indeed, the purpose of this flight was to return with another family member who would help them with the move. While alternate plans were in place for the pilot's work duties, there is no evidence from the NTSB narrative that alternate plans were discussed with the landlord (1996a).

\section{$\underline{\text { Accident } 3}$}

\section{$\underline{\text { Pilot }}$}

According to the NTSB, the private pilot had been certified 14 months prior to the accident (1996c). He held no instrument rating. His total flight time was 123.5 hours, with 14 hours at night and 3 hours of simulated instrument time. Within the preceding 90 days, he had logged 2 hours at night and no instrument time. He therefore was not certified to continue his flight into the deteriorating weather conditions.

\section{$\underline{\text { Aircraft }}$}

The accident aircraft was a Mooney M20E. According to the NTSB narrative (1996c), an annual inspection had been completed 11 months earlier. The only discrepancy mentioned was the lack of compliance with an airworthiness directive requiring the lubrication of all flight control systems. This non-compliance was not determined to have had an effect on the outcome of this flight, and the aircraft appears to have been otherwise satisfactory for flight.

\section{Environment}

The pilot placed three phone calls to the Seattle AFSS at 1354, 1844, and 2235 local time on the evening of August 1, 1996, to inquire about weather conditions forecast for his route of flight the following morning (NTSB, 1996c). Each time he was informed that marginal VFR conditions were expected. He decided to depart Friday Harbor that night instead to complete the flight before conditions deteriorated. Once in flight, he was advised by Seattle AFSS that the weather conditions were worsening at a faster than expected rate. The ceiling at Olympia had dropped to an 800 foot broken layer, and another pilot in flight was reporting difficulty maintaining VFR flight. The pilot of the accident flight opted to continue and flew into an area where the reported ceiling at the time of the accident was a 600 foot overcast layer. The ceiling in this area had been as high as 2,600 feet only 20 minutes earlier (NTSB, 1996c).

\section{External pressures}

According to an acquaintance, "the pilot, who owned a bowling alley, was returning to Oregon to run a major bowling tournament at the alley which was scheduled for the day on which the accident occurred" (NTSB, 1996c). Given the option of trying to fly out that night or wait for two days, after the tournament had begun, the pilot chose to fly that night. There is no evidence that the pilot discussed alternate plans with 
friends or employees concerning the running of the tournament should he not return in time.

Motivation

Jensen, Guilkey, and Hunter "believe that ... in situations where no one is watching, a commitment will be stronger for personal minimums than it would be for imposed minimums" (1998, p.3). The implication is that sufficient outside pressures weaken the will to abide by these personal minimums. These external pressures quickly become self-induced pressures, as pilots perceive that more is at stake for them personally. A cautionary note in the PAVE checklist warns the pilot that "[t]he more important the trip, the more tendency there is to compromise your personal minimums, and the more important it becomes to have alternate plans" (FAA, The Ohio State University, \& King Schools, 1996).

Inspection of Tables 1 through 4 shows that factors related to all four elements raised the overall risk associated with these flights. Yet, in spite of objective information indicating that flight was not wise, three pilots made a go decision. According to Hawkins, "[i]n simple terms, motivation reflects the difference between what a person can do and what he will do" (1987, p. 133). In each of the three accidents presented here, a qualified pilot contacted flight service prior to takeoff for one or more weather briefings. They all filed flight plans for the proposed flights. Two of the three were flight instructors. On the surface, they appear to be good, conscientious pilots.

The common denominator in the three accidents was the presence of an outside/self-induced pressure motivating them to complete a flight. In spite of thunderstorms, a rushed schedule, and an overloaded aircraft, one pilot allowed media commitments to make a decision for him. In spite of poor weather conditions at the departure airport and along the route of flight, one pilot allowed pressure from a landlord to make a decision for her. In spite of worsening weather conditions encountered en route, one pilot allowed a bowling tournament to make a decision for him.

Certain motivations, however, can help to ensure that a pilot will make a good decision when faced with rising risks. Copp (2000) tells of a flight in which the decision was made to not continue with flight in light of worsening weather conditions. In spite of being faced with rental car charges and the hassle of returning both the car and the airplane to their respective home bases over the course of the next week, he opted to land the aircraft and finish the trip on the ground. The presence of his wife and son were the motivating force behind the decision to discontinue flight. Deteriorated weather conditions at his destination validated his decision (Copp, 2000).

\section{CONCLUSION}

Use of the PAVE personal minimums checklist as an aid in the go/nogo decision-making process is an important step in preventing accidents such as these. Some minor changes to the checklist might be considered. For example, pilots might consider how many hours they have already flown in the preceding 24 hours when evaluating physical condition. Also, a line about hazardous weather avoidance would be appropriate in the environment section. And, given the strength of self-induced pressures to affect decision-making, it could be argued that the "Importance of Trip" note in the checklist be moved to the front of the checklist where it would be more prominent, at the outset alerting pilots to question their motivation to make a flight.

However, the personal minimums checklist is a valuable decision-making tool 
beyond the initial go/no-go decision. As conditions change, personal minimums may be exceeded at any time during flight. The checklist appears to be viable as an in-flight decision-making aid when considering whether to continue in flight.

Nonetheless, the checklist is frequently dependent on the subjective selfevaluation of the pilots. While determining the airworthiness of an aircraft or the hazards related to current weather should be a fairly straightforward task, external/selfinduced pressures can motivate a pilot to ignore personal limitations or in some other way rationalize a poor decision, either before or during flight. The answer may be to help pilots identify some personal positive motivating factor to consider when faced with a decision. For example, in each accident presented here, there were passengers aboard. A higher sense of responsibility to these passengers might be the motivating factor necessary to help ensure safe decision-making.

As the 1998 study indicated that those pilots surveyed were open to the use of aids in the go/no-go decision-making process, research should continue to focus on how to better deliver instruction regarding the effects of outside pressures and pilot motivation on decision-making and on more effective methods of dissemination and use of materials such as the PAVE checklist. Questions that might be addressed include:

1. Are pilots who are taught the proper use of a formal personal minimums checklist from Day 1 of training more likely to make good decisions, both before and during flight, in spite of external/self-induced pressures?

2. Should check airmen include the personal minimums tool as a part of checkrides, flight reviews, instrument proficiency checks, etc?
3. How do we teach pilots to be more honest with themselves and those around them? 


\section{Table 1}

Comparison of Pilot to PAVE Checklist

Checklist Item

Accident 1

Accident 2

Accident 3

Experience/ Currency

Physical Condition
- 1,484 hours total time

- $\quad 4.1$ hours actual and 4.0 hours simulated instrument in last 12 months

- Eight flights out of high altitude airports in preceding five years

$\checkmark$ Sleep history: April 7, $71 \frac{1}{2}-8$ 1/2 hours; April 8, 6 $1 / 2$ hours; April 9, 5 1/2 hours; April 10, unknownhotel check-in 1900, check-out 0622 April 11

- Some food in stomach

- No alcohol detected; some acetaminophen detected
- Recent instrument experience unknown

- Had flown into Cortland two days prior
- 3 hours total simulated instrument time

Not instrument rated
Sleep history: June 12, unknown; June 13, unknownmotel check-in 2001, wake-up call 0030 June 14

- No drugs or alcohol detected

- Under pressure to move out of current residence
- Sleep history: July 31, unknown; August 1,

- No drugs or alcohol detected

Note: Known pilot information taken from Aircraft Accident Report NTSB/AAR-97/02 and NTSB Accident Narratives NYC96FA126 and SEA96FA175. $\bullet=$ factor not considered to raise risk associated with flight; $\sqrt{ }=$ factor considered to raise risk associated with flight. 


\section{Table 2}

Comparison of Aircraft to PAVE Checklist

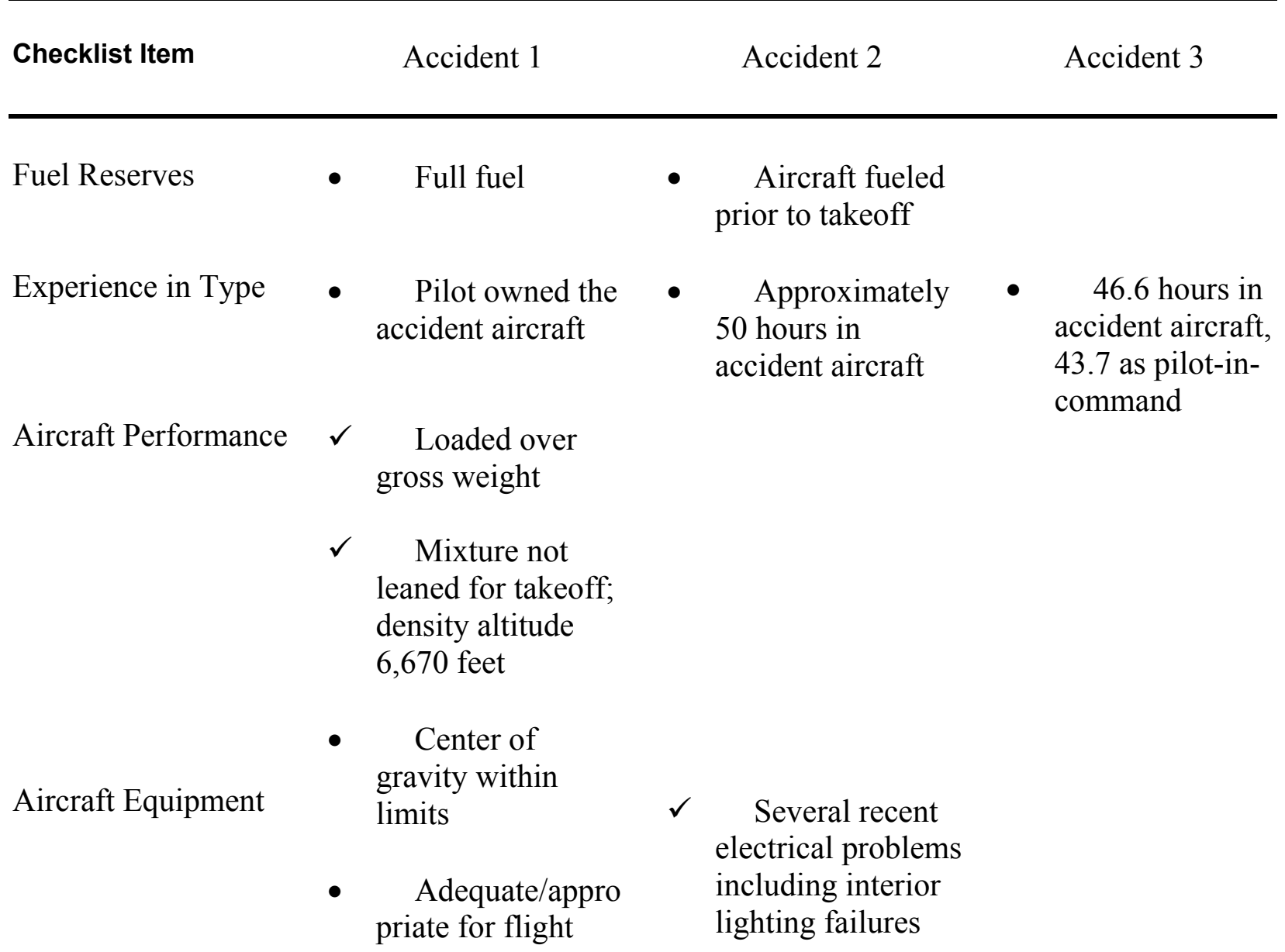

Note: Known aircraft information taken from Aircraft Accident Report NTSB/AAR-97/02 and NTSB Accident Narratives NYC96FA126 and SEA96FA175. $\bullet=$ factor not considered to raise risk associated with flight; $\sqrt{ }=$ factor considered to raise risk associated with flight. 
Table 3

Comparison of Environment to PAVE Checklist

Checklist Item

Accident 1

Accident 2

Accident 3

Airport Conditions

Weather

Weather for VFR

Weather For IFR

$$
\begin{aligned}
& \checkmark \text { Requested special } \\
& \text { VFR due to } \\
& \text { visibility }
\end{aligned}
$$

- Crosswind of 18-21 knots

- Runway length 6,691 feet

- Briefing obtained from Casper AFSS within hour prior to takeoff

$\checkmark$ Icing, severe turbulence, and IFR precautions

- Flight to be conducted under VFR
IFR departure procedure (rwy hdg to 2600 before turning) and alternate takeoff minimums (400 foot ceiling and $2 \mathrm{mi}$ visibility)
- Wind conditions not reported

- Runway length 4300 feet

- Obtained briefings from Buffalo FSS

- Obtained briefings from Seattle AFSS

- Marginal VFR conditions and rain showers forecast for following morning $1 / 4$ mile visibility at takeoff

\section{$\checkmark$ Informed of} worsening conditions shortly after takeoff

$\checkmark$ Entered area with 600 foot ceiling about 40 minutes into the flight

- Flight to be conducted under VFR

Note: Known environment information taken from Aircraft Accident Report NTSB/AAR-97/02 and NTSB Accident Narratives NYC96FA126 and SEA96FA175. $\bullet=$ factor not considered to raise risk associated with flight; $\sqrt{ }=$ factor considered to raise risk associated with flight. 
Table 4

Comparison of External Pressures to PAVE Checklist

Checklist Item

Accident 1

Accident 2

Accident 3

\begin{tabular}{|c|c|c|c|c|}
\hline \multirow[t]{2}{*}{ Trip Planning } & $\begin{array}{ll}\checkmark & \text { Trip to be } \\
& \text { completed } \\
\text { within eight } \\
\text { days }\end{array}$ & $\begin{array}{l}\checkmark \text { Trip planned to } \\
\text { be completed in } \\
\text { two days }\end{array}$ & \multirow{2}{*}{\multicolumn{2}{|c|}{$\begin{array}{l}\checkmark \text { Trip planned } \\
\text { to be } \\
\text { completed } \\
\text { overnight }\end{array}$}} \\
\hline & $\begin{array}{ll}\checkmark & \text { Media } \\
\text { commitments at } \\
\text { most stops }\end{array}$ & & & \\
\hline \multirow[t]{2}{*}{ Alternate Plans } & $\begin{array}{ll}\checkmark & \text { No alternate } \\
\text { plans known to } \\
\text { exist or be } \\
\text { discussed }\end{array}$ & $\begin{array}{l}\text { Alternate plans } \\
\text { discussed with } \\
\text { coworkers }\end{array}$ & \multirow[t]{2}{*}{$\checkmark$} & \multirow{2}{*}{$\begin{array}{l}\text { Alternate } \\
\text { plans not } \\
\text { known to have } \\
\text { been discussed } \\
\text { with } \\
\text { coworkers }\end{array}$} \\
\hline & & $\begin{array}{l}\checkmark \text { Alternate plans } \\
\text { not known to } \\
\text { have been } \\
\text { discussed with } \\
\text { landlord }\end{array}$ & & \\
\hline Personal Equipment & $\begin{array}{l}\text { - Adequate for } \\
\text { flight }\end{array}$ & $\begin{array}{l}\text { - Adequate for } \\
\text { flight }\end{array}$ & & $\begin{array}{l}\text { Adequate for } \\
\text { flight }\end{array}$ \\
\hline
\end{tabular}

Note: Known external pressure information taken from Aircraft Accident Report NTSB/AAR-97/02 and NTSB

Accident Narratives NYC96FA126 and SEA96FA175. $\bullet=$ factor not considered to raise risk associated with flight; $\sqrt{ }=$ factor considered to raise risk associated with flight. 


\section{REFERENCES}

Copp, R. W. (2000, April). Learning experiences: The toughest flying decisions. AOPA Flight Training, 12, 52-53.

Federal Aviation Administration, The Ohio State University, \& King Schools. (1996). Personal minimums checklist (Publication Nos. FAA-P-8740-56, AFS-810(1996)). Washington, DC: Federal Aviation Administration.

Federal Aviation Administration. (1991). Advisory circular: Aeronautical decision making (FAA Publication No. AC 60-22). Washington, DC: Author.

Federal Aviation Administration. (1987). Aeronautical decision making for student and private pilots (Report No. DOT/FAA/PM-86/41). Washington, DC: Author. (NTIS No. ADA182549)

General Operating \& Flight Rules, 14 C.F.R. § 91 (2001). Company.

Hawkins, F. H. (1987). Human factors in flight. Brookfield, VT: Ashgate Publishing

Hurt, H. H., Jr. (1965). Aerodynamics for naval aviators (US Navy Publication No. NAVWEPS 00-80T-80). Washington, DC: The Office of the Chief of Naval Operations.

Jensen, R. S., Guilkey, J. E., \& Hunter, D. R. (1998). An evaluation of pilot acceptance of the personal minimums training program for risk management (Report No. DOT/FAA/AM96/19). Washington, DC: Office of Aviation Medicine. (NTIS No. ADA340338)

Kirkbride, L. A., Jensen, R. S., Chubb, G. P., \& Hunter, D. R. (1996). Developing the personal minimums tool for managing risk during preflight go/no-go decisions (Report No. DOT/FAA/AM-96/19). Washington, DC: Office of Aviation Medicine. (NTIS. No. ADA313639)

National Transportation Safety Board. (1996a). NYC96FA126 Accident Narrative. Washington, DC: Author. Retrieved May 21, 2001 from the World Wide Web: http://www.ntsb.gov/ntsb/brief2.asp?ev_id=20001208X06081\&ntsbno=NYC96FA126\&akey=1

National Transportation Safety Board. (1996b). NYC96FA126 Accident Synopsis. Washington, DC: Author. Retrieved May 21, 2001 from the World Wide Web: http://www.ntsb.gov/ntsb/brief.asp?ev_id=20001208X06081\&key=1

National Transportation Safety Board. (1996c). SEA96FA175 Accident Narrative. Washington, DC: Author. Retrieved May 21, 2001 from the World Wide Web: http://www.ntsb.gov/ntsb/brief2.asp?ev_id=20001208X06611\&ntsbno=SEA96FA175\&akey=1

National Transportation Safety Board. (1996d). SEA96FA175 Accident Synopsis. Washington, DC: Author. Retrieved May 21, 2001 from the World Wide Web: http://www.ntsb.gov/ntsb/brief.asp?ev_id=20001208X06611\&key=1

National Transportation Safety Board. (1997). Aircraft accident report: In-flight loss of control and subsequent collision with terrain, Cessna 177B, N35207, Cheyenne, Wyoming, April 11, 1996 (Report No. NTSB/AAR-97/02). Washington, DC: Author. (NTIS No. PB97-910402)

National Transportation Safety Board. (1999). Annual review of aircraft accident data: U.S. general aviation calendar year 1996 (Report No. NTSB/ARG-99/01). Washington, DC: Author. (NTIS No. PB99-144230) 


\section{APPENDIX A \\ PERSONAL MINIMUMS CHECKLIST}

Think...

PILOT

AIRCRAFT

ENVIRONMENT

EXTERNAL

PRESSURES

Pilot:

Date Revised:

Reviewed with: (if applicable)

FAA-P-8740-56

AFS-810 (1996)

\section{PILOT}

Experience/Currency

Takeoffs/landings. in the last days

Hours in make/model................ in the last days

Instrument approaches. in the last (simulated or actual) days

Instrument flight hours in the last (simulated or actual) days

Terrain and airspace

Familiar

Physical Condition

Sleep in the last 24 hours

Food and water in the last hours

Alcohol None in the last hours

Drugs or medication. None in the last days

Stressful events. None in the last days 
Illnesses. None in the last days

AIRCRAFT

Fuel Reserves (Cross-Country)
VFR Day
hours
Night.
hours
IFR Day hours
Night hours

Experience in Type

Takeoffs/landings in the last in aircraft type days

Aircraft Performance

Establish that you have additional performance available over that required.

Consider the following:

- Gross weight

- Load distribution

- Density altitude

- Performance charts

Aircraft Equipment

Avionics familiar with equipment (including autopilot and GPS systems)

$\mathrm{COM} / \mathrm{NAV}$ equipment appropriate to flight

Charts current

Clothing. suitable for preflight and flight 
Survival gear...............appropriate for flight/terrain

ENVIRONMENT

Airport Conditions

Crosswind $\%$ of max $\mathrm{POH}$

Runway length........__ \% more than $\mathrm{POH}$

Weather

Reports and forecasts. not more than hours old

Icing conditions. .within aircraft/pilot capabilities

Weather for VFR

Ceiling Day feet

Night. feet

Visibility Day miles

Night. miles

Weather For IFR

Precision Approaches

Ceiling. feet above min.

Visibility mile(s) above min.

Non-Precision Approaches

Ceiling. feet above min.

Visibility mile(s) above min. 
Missed Approaches

No more than before diverting

Takeoff Minimums

Ceiling................ feet

Visibility.............__ mile(s)

\section{EXTERNAL PRESSURES}

Trip Planning

Allowance for delays minutes

Diversion or Cancellation Alternate Plans

Notification of person(s) you are meeting

Passengers briefed on diversion or cancellation plans and alternatives

Modification or cancellation of car rental, restaurant, or hotel reservations

Arrangement of alternative transportation (airline, car, etc.)

Personal Equipment

Credit card and telephone numbers available for alternate plans

Appropriate clothing or personal needs (eye wear, medication...) in the event of an unexpected stay 


\title{
!Importance of Trip
}

The more important the trip, the more tendency there is to compromise your personal minimums, and the more important it becomes to have alternate plans.

\begin{abstract}
Your Personal Minimums Checklist---
- $\quad$ An easy-to-use, personal tool, tailored to your level of skill, knowledge, and ability.

- Helps you control and manage risk by identifying even subtle risk factors

- $\quad$ Lets you fly with less stress and less risk
\end{abstract}

\section{Practice "Conservatism Without Guilt"}

Each item provides you with either a space to complete a personal minimum or a checklist item to think about. Spend some quiet time completing each blank and consider other items that apply to your personal minimums. Give yourself permission to choose higher minimums than those specified in the regulations, aircraft flight manuals, or other rules.

\section{How To Use Your Checklist}

Use this checklist just as you would one for your aircraft. Carry the checklist in your flight kit. Use it at home as you start planning a flight and again just before you make your final decision to fly.

Be wary if you have an item that's marginal in any single risk factor category. But if you have items in more than one category, you may be headed for trouble.

\section{If you have marginal items in two or more risk factors/categories, don't go!}

Periodically review and revise your checklist as your personal circumstances change, such as your proficiency, currency, or training. You should never make your mini-mums less restrictive unless a significant positive event has occurred. However, it is okay to make your minimums more restrictive at any time. Never make your minimums less restrictive when you are planning a specific flight, or else external pressures will influence you.

\section{Have a fun and safe flight!}

\section{FEDERAL AVIATION ADMINISTRATION AVIATION \\ SAFETY PROGRAMS \\ THE OHIO STATE UNIVERSITY KING SCHOOLS}

